\title{
Pyrexia: aetiology in the ICU
}

\author{
Daniel J. Niven ${ }^{1,2^{*}}$ and Kevin B. Laupland ${ }^{3}$
}

\begin{abstract}
Elevation in core body temperature is one of the most frequently detected abnormal signs in patients admitted to adult ICUs, and is associated with increased mortality in select populations of critically ill patients. The definition of an elevated body temperature varies considerably by population and thermometer, and is commonly defined by a temperature of $38.0^{\circ} \mathrm{C}$ or greater. Terms such as hyperthermia, pyrexia, and fever are often used interchangeably. However, strictly speaking hyperthermia refers to the elevation in body temperature that occurs without an increase in the hypothalamic set point, such as in response to specific environmental (e.g., heat stroke), pharmacologic (e.g., neuroleptic malignant syndrome), or endocrine (e.g., thyrotoxicosis) stimuli. On the other hand, pyrexia and fever refer to the classical increase in body temperature that occurs in response to a vast list of infectious and noninfectious aetiologies in association with an increase in the hypothalamic set point. In this review, we examine the contemporary literature investigating the incidence and aetiology of pyrexia and hyperthermia among medical and surgical patients admitted to adult ICUs with or without an acute neurological condition. A temperature greater than $41.0^{\circ} \mathrm{C}$, although occasionally observed among patients with infectious or noninfectious pyrexia, is more commonly observed in patients with hyperthermia. Most episodes of pyrexia are due to infections, but incidence estimates of infectious and noninfectious aetiologies are limited by studies with small sample size and inconsistent reporting of noninfectious aetiologies. Pyrexia commonly triggers a full septic work-up, but on its own is a poor predictor of culture-positivity. In order to improve culturing practices, and better guide the diagnostic approach to critically ill patients with pyrexia, additional research is required to provide more robust estimates of the incidence of infectious and noninfectious aetiologies, and their relationship to other clinical features (e.g., leukocytosis). In the meantime, using existing literature, we propose an approach to identifying the aetiology of pyrexia in critically ill adults.
\end{abstract}

Keywords: Pyrexia, Fever, Hyperthermia, Temperature, ICU, Etiology, Aetiology, Cause, Incidence

\section{Background}

Temperature is commonly measured as part of the routine assessment of patients admitted to adult ICUs. Normal body temperature is between 36.0 and $37.5{ }^{\circ} \mathrm{C}$ [1]. Elevated body temperature is detected in approximately $50 \%$ of patients admitted to adult ICUs [2-6]. In addition to being common, elevated body temperature is associated with increased mortality in subpopulations of critically ill patients including those with acute neurological conditions [7-9], noninfectious aetiologies of pyrexia [10], and medical patients that develop pyrexia in

\footnotetext{
* Correspondence: daniel.niven@ahs.ca

'Department of Critical Care Medicine and Community Health Sciences,

O'Brien Institute for Public Health, Cumming School of Medicine, University

of Calgary, Calgary, AB, Canada

${ }^{2}$ ICU Administration, Foothills Medical Centre, 3134 Hospital Drive NW,

Calgary, AB T2N 2T9, Canada

Full list of author information is available at the end of the article
}

the ICU [3]. Although the optimal approach to managing elevated body temperature in critically ill patients remains controversial [11-15], it is widely accepted that elevated body temperature is an evolutionarily conserved sign of an underlying physiologic stressor and its presence should trigger a systematic search for the aetiology.

In this article, we will review the contemporary literature investigating the aetiology and incidence of elevated body temperature among patients admitted to adult ICUs. We will begin by examining literature pertaining to the measurement of body temperature and definitions for what constitutes an elevated temperature. We will then focus on the aetiology of pyrexia in medical and surgical patients with and without acute neurological conditions, including a brief discussion on hyperthermia syndromes. Because immunocompromised patients present 
a distinct set of aetiologic considerations, they will not be reviewed.

\section{Literature review}

Relevant articles were identified through three sources. First, a semistructured literature review was conducted using MEDLINE from 1966 to 15 January 2016. The objective of the search was to identify English-language articles that reported on the aetiology or incidence of pyrexia among medical and surgical patients admitted to adult ICUs. The search used a combination of exploded Medical Subject Heading terms and text words that included synonyms for pyrexia and ICU, and a validated search filter for identifying studies investigating aetiology [16]. Titles and abstracts were screened for relevance, and appropriate full-length articles were retrieved for appraisal. Second, additional articles were identified using the "related articles" feature in PubMed and by handsearching bibliographies of included studies, previously published reviews [17, 18], and relevant societal guidelines [19]. Finally, the authors' personal files were screened for other articles of relevance.

\section{Body temperature measurement and definitions}

Normal body temperature is between 36.0 and $37.5{ }^{\circ} \mathrm{C}$, with intraindividual variability of $0.5-1.0{ }^{\circ} \mathrm{C}$ depending on the time of day (low in early morning, peak in early afternoon/late evening) [1,20]. Elevated body temperature is classified as pyrexia or hyperthermia. Although these two terms are often used interchangeably, their biological mechanisms and response to therapy are different-thus their distinction is important and will be maintained in this article. Pyrexia, also referred to as fever, is an adaptive response to a physiologic stress that is tightly regulated through endogenous pyrogenic and anti-pyretic pathways, and is associated with an increase in the hypothalamic set point [18]. As such, the elevated body temperature in patients with pyrexia responds to pharmacologic anti-pyretic therapies such as acetaminophen. On the contrary, the elevated body temperature that occurs in hyperthermia syndromes often exceeds $41.0^{\circ} \mathrm{C}$, and reflects a pathologic increase in body temperature that is not associated with an increased hypothalamic set point [21]. This elevated temperature in hyperthermia is therefore not responsive to pharmacologic anti-pyretic therapy. For this article, pyrexia and fever will be used interchangeably, but hyperthermia will refer to the syndrome that accompanies specific environmental, pharmacologic, or endocrine stimuli (Fig. 1).

There is considerable heterogeneity among clinicians in the temperature threshold used to define an episode of pyrexia or hyperthermia [22]. This heterogeneity includes not only temperature variability related to the normal diurnal variability in body temperature, but also differences in the thermometer used to measure temperature. Guidelines in critically ill adults recommend measuring temperature using a central thermometer that provides a direct measure of the core temperature [19]. Examples of such central thermometers include the pulmonary artery catheter, and urinary bladder, esophageal, and rectal thermistors. Although these thermometers provide the most accurate assessment of core body temperature, they are not commonly employed as the primary method of temperature measurement in critically ill patients. Rather, temperature is commonly measured using thermometers that measure temperature from a peripheral site (e.g., tympanic membrane, temporal artery, axilla, mouth) and use proprietary algorithms to convert the measured temperature into a core temperature $[22,23]$. Unfortunately, peripheral thermometers are among the least accurate, especially in patients with fever or hypothermia. A recent systematic review and meta-analysis found that, compared with central thermometers, the sensitivity and specificity of peripheral thermometers for the detection of fever was $64 \%$ (95\% CI 55-72\%) and $96 \%$ (95\% CI 93-97\%), respectively [23]. Therefore, for patients where exact temperature measurement is critical or when measured temperature is not congruent with the clinical picture, confirmation with a central device is a key step in determining the underlying aetiology.

A systematic review of observational studies in febrile critically ill adults reported five different definitions of pyrexia among the nine included studies, with $38.3{ }^{\circ} \mathrm{C}$ being the most frequently cited threshold [4]. A metaanalysis examining thermometer accuracy found seven distinct definitions of pyrexia, with $37.8{ }^{\circ} \mathrm{C}$ being the most frequently cited temperature threshold [23]. A multinational survey of 139 ICUs in 23 countries found 14 discreet temperature thresholds used to define pyrexia with a range of $37-40{ }^{\circ} \mathrm{C}$ and a median (interquartile range) of $38.2{ }^{\circ} \mathrm{C}\left(38.0-38.5{ }^{\circ} \mathrm{C}\right)$ [22]. Guidelines in critically ill adults define pyrexia as a temperature of $38.3^{\circ} \mathrm{C}$ or greater, with the caveat that a lower threshold should be used in immunocompromised patients who are more likely to harbor a severe illness without significant elevation in body temperature [19]. Although not a well-established inherited or acquired state of immunodeficiency, being critically ill presents multiple factors that may impair immune system function and the likelihood of responding to physiologic stress through an elevation in body temperature. These factors include but are not limited to the presence of invasive catheters, decreased mobility and ability to communicate, frequent use of anti-pyretic analgesic drugs and/or broad-spectrum antimicrobials, and extracorporeal forms of organ system support. Therefore, in this article a core body temperature of $38.0^{\circ} \mathrm{C}$ or greater will represent pyrexia or hyperthermia. 


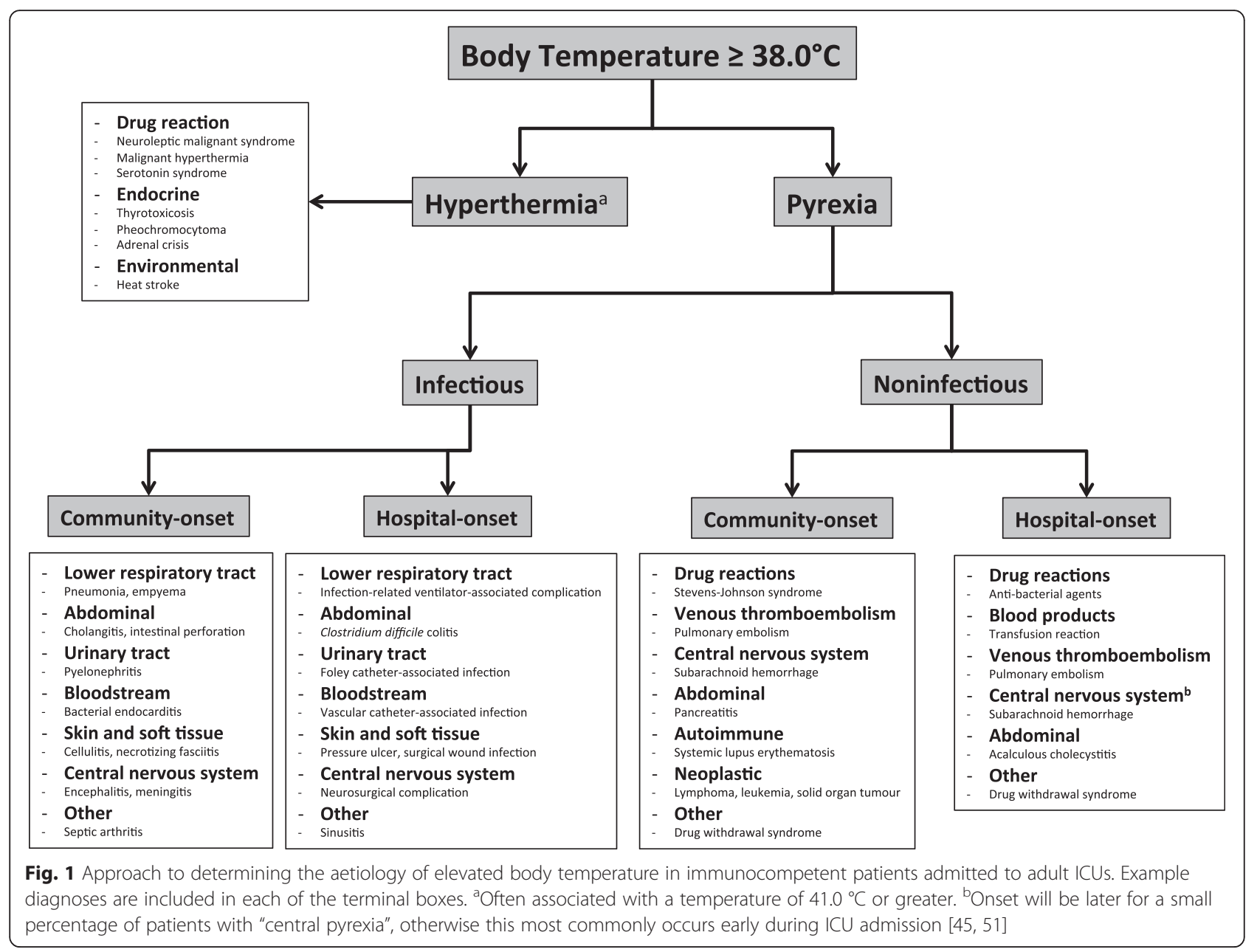

High pyrexia will be defined as a temperature of $39.5{ }^{\circ} \mathrm{C}$ or greater [18].

\section{Aetiology and incidence of hyperthermia and pyrexia}

The absolute body temperature and the response to pharmacological anti-pyretic therapy are often useful in distinguishing between hyperthermia and pyrexia. A temperature that exceeds $41.0{ }^{\circ} \mathrm{C}$ and is not responsive to pharmacologic anti-pyretic therapy is more commonly observed in patients with hyperthermia. Therefore, patients with milder elevations in body temperature and/or those whose temperature decreases when administered pharmacologic anti-pyretic drugs are unlikely to be suffering from a hyperthermia syndrome. On the contrary, the absolute temperature is not as helpful in differentiating between infectious and noninfectious pyrexia. Rather, this requires careful examination and investigation for a broad number of infectious and noninfectious diagnoses (Fig. 1). The following sections will provide an overview of several common aetiologies of hyperthermia and pyrexia, followed by presentation of data supporting their incidence in medical, surgical, and neurologically impaired patients.

\section{Hyperthermia syndromes}

The hyperthermia syndromes, generally characterized by severely elevated body temperature, include: environmental hyperthermia including heatstroke [24]; druginduced hyperthermia, including malignant hyperthermia [21], neuroleptic malignant syndrome [25], and serotonin syndrome [26]; and endocrine causes including thyrotoxicosis, pheochromocytoma, and adrenal crisis [27]. Heatstroke is defined clinically as a core temperature greater than $40{ }^{\circ} \mathrm{C}$ associated with central nervous system impairment and multisystem organ failure [24]. Classic heat stroke occurs among older, chronically ill, and debilitated individuals during heat waves, wherein a high external temperature overwhelms the body's thermoregulatory capacity to dissipate the heat [28]. Exertional heat stroke typically occurs in young, otherwise healthy individuals undergoing strenuous physical activity, wherein the excessive heat production disrupts usual thermal homeostasis [28]. Complications 
of heat stroke include rhabdomyolysis, disseminated intravascular coagulation, renal and liver failure, and severe metabolic derangements including hypoglycemia, lactic acidosis, and hyperkalemia [24]. Malignant hyperthermia occurs among patients with inherited mutations in the ryanodine receptor and is characterized by the acute onset of muscle rigidity, hyperthermia, and acidosis in response to exposure to inhalational anesthetics or depolarizing paralytic medications [21]. Neuroleptic malignant syndrome is characterized by the insidious onset of muscle rigidity, hyperthermia, and mental status changes that occur because of the administration of centrally-acting dopamine antagonists, usually typical or atypical antipsychotics, but may also include antinauseant medications such as metoclopramide [25]. Serotonin syndrome presents with the rapid onset of hyperthermia and other signs of autonomic instability including tachycardia, mydriasis, and diaphoresis, as well as cognitive and neuromuscular changes that may include tremor, hyperreflexia, and clonus in patients with excess central and peripheral serotonergic agonism [26]. Typically, serotonin syndrome occurs following intentional selfpoisoning with prescription or illicit serotonergic agents, but may also occur in the context of therapeutic drug use, including antibiotic therapy with linezolid, or inadvertent drug interactions [26]. Endocrine emergencies occasionally present with hyperthermia. While less commonly the case for pheochromocytoma and adrenal crisis, hyperthermia is a common feature of severe thyrotoxicosis, and is one of the diagnostic features of thyroid storm [27].

\section{Pyrexia due to infectious aetiologies}

Many episodes of pyrexia are due to infections, and can be broadly divided according to whether they are community onset or hospital onset, with hospital-onset infections manifesting 48 hours or more after admission to hospital [29]. Whether community onset or hospital onset, the most common source of infection in immunocompetent critically ill patients is the lower respiratory tract $[12,30]$. For patients admitted from the community this typically represents an infectious bronchitis, or community-acquired pneumonia with or without its associated complications such as abscess or empyema. Most lower respiratory tract infections that take origin in the community are due to a viral pathogen such as human rhinovirus or influenza $\mathrm{A} / \mathrm{B}$, with a smaller portion being bacterial, such as Streptococcus pneumoniae, less commonly mycobacterial, or rarely fungal [31]. For mechanically ventilated patients, hospital-onset lower respiratory tract infection is typically an infectious tracheobronchitis or ventilator-associated pneumonia. These events are usually due to bacteria such as Staphylococcus aureus, Gram-negative bacilli, and less frequently fungal aetiologies.
Peritonitis due to intra-abdominal infection is a common community-onset infectious syndrome [30]. Frequently encountered diagnoses include intestinal perforation, intestinal ischemia with consequential perforation or secondary bacterial invasion of the bloodstream, cholecystitis, appendicitis, perforated diverticular abscess, or hepatic abscess. For patients recovering from abdominal surgery, especially those with intestinal perforation who may have had contamination of the peritoneal space with intestinal contents, intra-abdominal abscess should be sought as a source of pyrexia; otherwise this is generally an uncommon source of new hospital-onset infection. However, colitis due to Clostridium difficile infection should not be overlooked in the hospitalized patient with fever and diarrhea, especially in patients who have been treated with broadspectrum antibiotics [32].

Urinary tract infection is another common aetiology of pyrexia [12]. While the majority of community-onset lower urinary tract infections are not associated with fever and systemic symptoms, patients admitted to hospital and especially the ICU owing to a urinary tract infection typically have infection of the upper urinary tract wherein high fever and other signs of sepsis are common. In patients whose urinary tract infection develops while in the ICU, this is usually the result of an accumulated biofilm on the urinary bladder catheter. In these patients, not only is the bladder catheter the source of the infection, it may also mask the development of symptoms classically ascribed to infection of the urinary tract, and pyrexia may be the only presenting sign [33]. For community-onset infections, the organisms most frequently detected include Escherichia coli, Klebsiella pneumoniae, and Enterococcus species [34], whereas Pseudomonas aeruginosa is frequently isolated among patients with a urinary tract infection acquired in the ICU [35].

Any infection, but especially those in the lower respiratory tract, abdomen, or urinary tract, can invade the bloodstream. Given that bloodstream infection can also be primary or catheter related, the bloodstream is a common site of infection in critically ill patients with pyrexia $[3,5,19,36]$. Among patients admitted to the ICU owing to a severe bloodstream infection that is community onset, the most common pathogens are $E$. coli, S. aureus, and S. pneumoniae [37]. For those infections that are hospital onset, S. aureus and E. coli are also the two most common pathogens, followed by Gram-negative Enterobacteriaceae and Enterococcus faecalis [37]. Risk factors for developing a severe bloodstream infection (community or hospital onset) include older age and the presence of underlying medical comorbidities especially diabetes mellitus, dialysis-dependent renal failure, cancer, lung disease, 
and alcoholism [37]. Fungemia with Candida albicans and non-albicans Candida species is important to consider as a cause of pyrexia that develops in hospital, especially in patients with risk factors such as recent surgical operation, sepsis, treatment with parenteral nutrition, and/or broad-spectrum antibacterial agents. Although rates of catheter-related bloodstream infection have decreased considerably owing to use of infection prevention bundles and early removal of unnecessary catheters $[38,39]$, this remains an important source of pyrexia in patients admitted to ICUs. While classically thought to present negligible risk, the infectious risk associated with arterial catheters is similar to central venous catheters $[40,41]$. Coagulasenegative staphylococci are the most common pathogen isolated in patients with catheter-related bloodstream infection, with other common organisms including $S$. aureus, enterococcal species, and Gram-negative Enterobacteriaceae $[42,43]$.

Other sources of infection include the skin and soft tissue, bone/joints, central nervous system, and ethmoid and maxillary sinuses [30]. Diagnoses such as cellulitis and necrotizing fasciitis commonly take origin in the community, although they may rarely be hospital onset. Skin breakdown particularly in the sacral area is a common problem in patients with long ICU or hospital lengths of stay, and these areas may become infected. In addition, any operative wound can become colonized and ultimately infected. Hospital-onset infections of the central nervous system are uncommon outside the neurosurgical setting; however, among patients with persistent bacteremia and prolonged pyrexia, consideration should be given to potential seeding of the paraspinal and/or epidural spaces. Finally, for patients with prolonged insertion of nasogastric and/or nasotracheal tubes, sinusitis commonly develops, and may be responsible for pyrexia that is not accompanied by other systemic signs of infection [44].

\section{Pyrexia due to noninfectious aetiologies}

Noninfectious diagnoses are also common causes of pyrexia in adult ICUs, especially among patients with an acute neurological condition [45]. Unless there are obvious signs and symptoms of the particular noninfectious problem, such as an exanthem in the context of a drug reaction or asymmetric leg edema in the context of deep vein thrombosis, these diagnoses are often not made until infectious aetiologies have been ruled out by detailed examination and an appropriate set of investigations. Similar to infectious aetiologies, noninfectious aetiologies can be grouped according to community or hospital onset. Although there may be a fair bit of overlap between the types of noninfectious community and hospital-onset problems responsible for pyrexia, this distinction is important because autoimmune and neoplastic aetiologies rarely develop in hospital. On the contrary, blood products and medications are commonly prescribed to hospitalized patients, and thus transfusion reactions and drug hypersensitivity, in particular to antimicrobial or antiepileptic agents, are frequent causes of noninfectious fever that develops in hospital. In addition, despite meticulous attention to appropriate prescription of venous thromboembolism prophylaxis, deep vein thrombosis and pulmonary embolism can be the source of a new episode of pyrexia, especially if complicated by septic thrombophlebitis. Abdominal sources may also be responsible for a noninfectious fever. Patients admitted to the ICU with pancreatitis may be febrile at ICU admission; however, fever may recur in hospital if pancreatitis is severe and complicated by necrosis and/or pseudocyst formation. While acalculous cholecystitis is not a typical diagnosis at ICU admission, it commonly develops in patients recovering from nonbiliary surgery and/or in those with significant periods of hypotension [46]. Although the mechanism behind the development of early postoperative fever remains unclear, and may or may not involve lung atelectasis [47], earlyonset fever is commonly noninfectious in origin for patients admitted to the ICU following elective surgery [2]. For patients admitted to the ICU with a neurological condition such as subarachnoid hemorrhage, traumatic brain injury, or intracerebral hemorrhage, pyrexia that occurs within the first couple days of ICU admission is most likely central fever due to the temperature dysregulation associated with the neurological injury rather than another infectious or noninfectious process.

\section{Incidence of pyrexia and aetiologies}

The incidence of pyrexia among critically ill adults depends on the defining temperature threshold and the population studied (Table 1). A systematic review of nine observational studies in patients admitted to the ICU without an acute neurological condition found that the fever incidence varied between 26 and $88 \%$ [4]. The largest studies were from Barie et al. [2] and Laupland et al. [3]. Defined as a temperature of $38.2{ }^{\circ} \mathrm{C}$ or greater, Barie and colleagues found that fever was present in $26 \%$ of 2419 patients admitted to their surgical ICU over a 14-month period [2]. Infections were responsible for $46 \%$ of febrile episodes, and were more likely in patients whose fever occurred at the time of admission following emergency surgery. On the contrary, among patients admitted to the ICU following elective surgery, early fever within 72 hours of admission was more likely to be noninfectious, and infectious aetiologies did not emerge until after 72 hours in the ICU. Defined as a temperature $38.3{ }^{\circ} \mathrm{C}$ or greater, Laupland and colleagues found that the cumulative incidence of fever was $44 \%$ 
Table 1 Studies reporting the aetiology of pyrexia in immunocompetent patients admitted to adult ICUs with or without an acute neurological condition

\begin{tabular}{|c|c|c|c|c|c|c|c|}
\hline \multirow[b]{2}{*}{ Study } & \multirow[b]{2}{*}{ Setting } & \multirow[b]{2}{*}{ Design } & \multirow[b]{2}{*}{$\begin{array}{l}\text { Total } \\
\text { patients (n) }\end{array}$} & \multirow[b]{2}{*}{$\begin{array}{l}\text { Episodes of } \\
\text { pyrexia }(n)\end{array}$} & \multirow[b]{2}{*}{$\begin{array}{l}\text { Pyrexia } \\
\text { definition }\left({ }^{\circ} \mathrm{C}\right)\end{array}$} & \multicolumn{2}{|l|}{ Aetiology } \\
\hline & & & & & & Infectious diagnosis $(n, \%)^{a}$ & Noninfectious diagnosis $(n, \%)^{a}$ \\
\hline \multicolumn{8}{|l|}{ No acute neurological condition } \\
\hline Circiumaru et al., 1999 [56] & $\begin{array}{l}\text { Medical-surgical } \\
\text { ICU }\end{array}$ & $\begin{array}{l}\text { Prospective observational } \\
\text { study }\end{array}$ & 93 & 70 & $\geq 38.4$ & $\begin{array}{l}\text { Total }(37,53) \text { Respiratory }(15,21) \mathrm{BSI} \\
(9,13) \text { Abdominal }(5,7) \text { Other }(8,11)\end{array}$ & $\begin{array}{l}\text { Total }(33,47) \text { ARDS }(4,6) \mathrm{MI}(3,4) \\
\text { Vasculitides }(2,3) \text { Pancreatitis }(1,1) \\
\text { Atelectasis }(1,1) \text { GVHD }(1,1) \mathrm{ICH} \\
(1,1) \text { Unclear }(20,29)^{\mathrm{b}}\end{array}$ \\
\hline Peres Bota et al., 2004 [57] & Medical-surgical ICU & $\begin{array}{l}\text { Prospective observational } \\
\text { study }\end{array}$ & 493 & 139 & $\geq 38.3$ & Total $(76,55)$ & $\begin{array}{l}\text { Total }(63,45) \text { Postoperative }(27,19) \\
\text { Cerebral hemorrhage }(20,14) \text { Trauma } \\
(5,4) \operatorname{ARDS}(3,2) \mathrm{Ml}(2,1) \text { Pancreatitis } \\
(3,2) \mathrm{Gl} \text { bleed }(3,2)\end{array}$ \\
\hline Barie et al., 2004 [2] & Surgical ICU & $\begin{array}{l}\text { Prospective observational } \\
\text { study }\end{array}$ & 2419 & 626 & $\geq 38.2$ & Total $(286,46)^{c}$ & Total $(330,53)^{c}$ \\
\hline Laupland et al., 2008 [3] & $\begin{array}{l}3 \text { medical-surgical } \\
\text { ICUs, } 1 \text { CVICU }\end{array}$ & $\begin{array}{l}\text { Retrospective observational } \\
\text { study }\end{array}$ & $20,466^{\mathrm{d}}$ & 10,730 & $\geq 38.3$ & $\begin{array}{l}\text { Culture-positive }(1847,17) \mathrm{BSI} \\
(1004,9)\end{array}$ & Culture-negative $(8883,83)$ \\
\hline Niven et al., 2011 [36] & $\begin{array}{l}3 \text { medical-surgical } \\
\text { ICUs, } 1 \text { CVICU }\end{array}$ & $\begin{array}{l}\text { Retrospective observational } \\
\text { study }\end{array}$ & 7535 & $100^{e}$ & $\geq 38.3$ & $\begin{array}{l}\text { Total }(73,73) \text { Pneumonia }(51,51) \\
\text { BSI }(6,6) \text { Other }(15,15)\end{array}$ & Total $(27,27)$ \\
\hline Gozzoli et al., 2001 [58] & Surgical ICU & $\mathrm{RCT}$ & 38 & 38 & $\geq 38.5$ & Total $(18,47)$ & Total $(20,53)$ \\
\hline Niven et al., 2013 [59] & $\begin{array}{l}2 \text { medical-surgical } \\
\text { ICUs }\end{array}$ & $\mathrm{RCT}$ & 26 & 26 & $\geq 38.3$ & $\begin{array}{l}\text { Total }(23,88) \text { Respiratory }(15,58) \text { UTI } \\
(2,8) \text { BSI }(1,4) \text { Other }(5,19)\end{array}$ & Total $(3,12)$ \\
\hline Schortgen et al., 2012 [11] & $\begin{array}{l}7 \text { medical-surgical } \\
\text { ICUs }\end{array}$ & RCT & 200 & 200 & $>38.3$ & $\begin{array}{l}\text { Total }(200,100)^{f} \text { Lungs }(138,69) \\
\text { Abdomen }(13,7) \text { Genitourinary }(12,6) \\
\text { Other }(28,14) \text { Unknown }(9,5)\end{array}$ & Not applicable \\
\hline Young et al., 2015 [12] & $\begin{array}{l}23 \text { medical-surgical } \\
\text { ICUs }\end{array}$ & $\mathrm{RCT}$ & 700 & 700 & $>38.0$ & $\begin{array}{l}\text { Total }(700,100)^{f} \text { Respiratory }(237,34) \\
\text { Abdominal }(92,13) \text { UTI }(68,10) \text { BSI } \\
(42,6) \text { Skin/soft tissue }(54,8) \text { Other } \\
(207,30)\end{array}$ & Not applicable \\
\hline \multicolumn{8}{|l|}{ Acute neurological condition } \\
\hline Commichau et al., 2003 [49] & Neurological ICU & $\begin{array}{l}\text { Prospective observational } \\
\text { study }\end{array}$ & 387 & 87 & $\geq 38.3$ & $\begin{array}{l}\text { Total }(45,52)^{9} \text { Respiratory }(37,42) \\
\text { Clostridium difficile }(4,4) \text { UTI }(3,3) \\
\text { Sinusitis }(1,1)\end{array}$ & Total $(2,2)$ DVT $(2,2)$ \\
\hline Rabinstein et al., 2007 [45] & Neurological ICU & $\begin{array}{l}\text { Prospective observational } \\
\text { study }\end{array}$ & 93 & 93 & $\geq 38.3$ & $\begin{array}{l}\text { Total }(62,67) \text { Respiratory }(46,49) \\
\text { Other }(16,17)\end{array}$ & $\begin{array}{l}\text { Total }(31,33) \text { Central fever }(27,29) \\
\text { Alcohol withdrawal }(3,3) \text { Phenytoin } \\
\text { toxicity }(1,1)\end{array}$ \\
\hline Hocker et al., 2013 [51] & Neurological ICU & $\begin{array}{l}\text { Retrospective observational } \\
\text { study }\end{array}$ & 526 & 526 & $>38.3$ & Total $(280,53)$ & Total $(246,47)$ \\
\hline
\end{tabular}

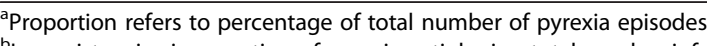

${ }^{b}$ Inconsistencies in reporting of pyrexia aetiologies; total number infectious and noninfectious aetiologies did not total the number of pyrexia episodes

'Detailed data for infectious and noninfectious aetiologies presented in graphical format only

${ }^{\mathrm{d} A}$ total of 24,204 ICU admissions among 20,466 patients

e Convenience sample of 100 randomly selected patients. Total number of patients with fever during study period was 2216

Both Schortgen et al. [11] and Young et al. [12] preferentially enrolled patients with suspected or confirmed infection

${ }^{9}$ Forty-two pyrexia episodes did not have a clear aetiology

ARDS acute respiratory distress syndrome, BSI bloodstream infection, CVICU cardiovascular intensive care unit, DVT deep vein thrombosis, GI gastrointestinal, GVHD graft versus host disease, ICH intracerebral

hemorrhage, $M I$ myocardial infarction, $R C T$ randomized controlled trial, UTI urinary tract infection 
among 20,466 critically ill adults with a broad range of admission diagnoses, with the highest incidence among trauma/neurologic patients [3]. Cultures from blood, urine, sputum, cerebrospinal fluid, and/or other sterile fluid were positive in $17 \%$ and $31 \%$ of fever and high fever episodes, respectively [3]. Bloodstream infection occurred in $9 \%$ and $19 \%$ of fever and high fever episodes, respectively. Culture-positivity was most likely among medical patients. However, this study probably underestimated the incidence of infectious fever because the authors did not systematically evaluate the results of diagnostic tests other than cultures for identifying infection [3]. Another study in the same health region that undertook a detailed chart review to investigate pyrexia management practices in 100 medical and surgical critically ill patients without an acute neurological condition found that infections were responsible for $73 \%$ of pyrexia episodes, with pneumonia the most common infection, occurring in $70 \%$ of infectious fevers [36]. This is consistent with a large, prospective study of infection occurrence in 71 ICUs in Italy, wherein the most common source of infection was pneumonia [30].

Unfortunately, the current literature does not consistently document the incidence of noninfectious aetiologies of pyrexia. Similarly, the incidence of the hyperthermia syndromes among ICU patients with an elevated body temperature is not clear.

Among critically ill patients with an acute neurological condition, the reported incidence of fever varies between 23 and $51 \%[6,48-50]$. The largest study investigating the epidemiology of fever among patients admitted to the ICU with an acute neurological condition is that of Rincon et al. [6]. Of 13,587 patients admitted to 94 ICUs in the United States, 6965 (51 \%) had fever defined as a temperature of $37.5{ }^{\circ} \mathrm{C}$ or greater. The incidence of fever was highest among patients with traumatic brain injury (60\%) or aneurysmal subarachnoid hemorrhage (54\%), and lowest among patients with acute ischemic stroke (37 \%) [6]. Unfortunately, Rincon and colleagues did not report on the aetiologies of pyrexia, and therefore estimates of the occurrence of infectious and noninfectious fever in neurological patients derive from smaller studies (Table 1). Among 93 patients admitted to a neurological ICU in the United States who developed pyrexia, infection was the cause in 62 patients $(67 \%)$ with noninfectious causes accounting for the other $31(33 \%)$ patients [45]. Infections were more common in patients with traumatic brain injury, whereas a noninfectious cause, most probably central fever, was more likely in patients with subarachnoid hemorrhage. Admission diagnosis of subarachnoid hemorrhage (odds ratio (OR) 11.79, $95 \%$ CI 3.0-59.4) and fever onset within 72 hours of ICU admission (OR 2.21, 95 \% CI 1.22-4.34) were statistically significant predictors of noninfectious fever [45]. Hocker and colleagues examined the occurrence of infectious and noninfectious aetiologies of fever in 526 patients admitted to a neurological ICU in the United States [51]. Because their objective was to develop a model predictive of the probability of central fever, they unfortunately excluded patients with other noninfectious causes of pyrexia. Nonetheless, they found that fever was infectious in $53 \%$ and central in $47 \%$. The combination of negative cultures (urine, blood, respiratory secretions, cerebrospinal fluid, peritoneal fluid, stool, sinus aspirates, and $C$. difficile PCR), an absence of infiltrate on chest radiograph, the diagnosis of subarachnoid hemorrhage, intraventricular hemorrhage, or tumor, and the onset of fever within 72 hours of admission predicted central fever with a probability of 0.90 [51].

\section{Investigations in patients with hyperthermia or pyrexia}

There is a relative lack of data pertaining to the approach to determining the aetiology of pyrexia. In a multinational survey of temperature management practices in 139 general medical-surgical ICUs, $59 \%$ of respondents indicated that new pyrexia triggers a full septic work-up, mostly via specific physician order, not a standardized protocol [22]. In a study examining management practices among febrile critically ill adults without an acute neurological condition, Niven et al. [36] found that $89 \%$ of the population had at least one culture sent to the laboratory for analysis within the first 48 hours of fever onset. The most common culture was a blood culture (73\%), followed by urine culture (62\%) and respiratory secretion culture (61\%). A chest radiograph was ordered in nearly all study participants $(95 \%)$ within 48 hours of fever onset [36].

Not surprisingly, given the paucity of studies describing the approach to determining the aetiology of pyrexia in patients admitted to ICUs, there is a similar lack of data describing the yield of such investigations in febrile patients. A series of three retrospective cohort studies in trauma patients admitted to one surgical/trauma ICU in the United States examined the relationship between the presence of fever and/or leukocytosis and: the ordering of urine [52], blood [53], and respiratory secretion [54] cultures; or the occurrence of urinary tract, bloodstream, and lower respiratory tract infections, respectively. For each fluid cultured, the results were generally the same; namely, a strong relationship between the presence of pyrexia and the ordering of urine [52], blood [53], and respiratory secretion [54] cultures, but no significant relationship between the presence of pyrexia and positive culture from the urine, blood, or lower respiratory tract. In a meta-analysis, Coburn et al. [55] examined clinical and laboratory features predictive of bacteremia in immunocompetent adults. The majority of the 35 included 
studies did not include critically ill patients; however, according to their meta-analysis, irrespective of the severity of pyrexia, elevated body temperature was not independently associated with the presence of bacteremia [55]. In addition, the absence of pyrexia was not sufficient to rule out bacteremia (temperature $\geq$ $38.3{ }^{\circ} \mathrm{C}$, negative likelihood ratio (LR) $0.80,95 \%$ CI $0.61-$ 1.0). The presence of shaking chills or rigors was modestly predictive of bacteremia (positive LR 4.7, 95 \% CI 3.07.2), whereas the absence of the systemic inflammatory response syndrome (SIRS) was the strongest predictor of negative blood cultures (negative LR 0.09, 95 \% CI 0.03-0.26).

Guidelines recommend a clinically driven, cost-conscious approach, rather than a protocolized, dogmatic approach, to obtaining cultures and imaging studies in critically ill patients with pyrexia [19]. Based on existing literature that suggests a poor association between pyrexia and the likelihood of a positive culture, yet a high likelihood that pyrexia heralds the presence of an infection, most infections are likely diagnosed based on clinical and radiographic findings. Therefore, we suggest for immunocompetent patients with an elevated body temperature that investigations should be guided by the clinical probability of the aetiologies outlined in Fig. 1. Blood cultures should be obtained in any patient with rigors, and may be avoided in febrile patients without concomitant SIRS.

\section{Conclusions}

Whether due to pyrexia or a hyperthermia syndrome, elevated body temperature is commonly encountered in patients admitted to adult ICUs. Although estimates of the incidence of infectious and noninfectious aetiologies are derived from studies with small sample size and inconsistent reporting of noninfectious aetiologies, current literature suggests that pyrexia is most frequently the sign of an infection. Among patients admitted to the ICU following surgery and/or an acute neurological condition, early fever may indicate a noninfectious process. Pyrexia commonly triggers a full septic work-up, but on its own is a poor predictor of culture-positivity. In order to improve culturing practices, and better guide the diagnostic approach to critically ill patients with pyrexia, additional research is required to provide more robust estimates of the incidence of infectious and noninfectious aetiologies, and their relationship to other clinical features. In the meantime, we suggest that investigations in patients with an elevated body temperature should be guided by the clinical probability of the aetiologies outlined in our proposed diagnostic approach.

\section{Abbreviations}

$L R$, likelihood ratio; $O R$, odds ratio; SIRS, systemic inflammatory response syndrome

\section{Authors' contributions}

Both authors contributed equally to the conception and design of the article. DJN drafted the full manuscript, and KBL contributed key revisions to the intellectual content. Both authors gave final approval of the version to be published.

\section{Competing interests}

The authors declare that they have no competing interests.

\section{Author details}

'Department of Critical Care Medicine and Community Health Sciences, O'Brien Institute for Public Health, Cumming School of Medicine, University of Calgary, Calgary, AB, Canada. ${ }^{2} \mathrm{C} U$ Administration, Foothills Medical Centre, 3134 Hospital Drive NW, Calgary, AB T2N 2T9, Canada. ${ }^{3}$ Department of Medicine, Royal Inland Hospital, 311 Columbia Street, Kamloops, BC V2C 2T1, Canada.

Published online: 01 September 2016

\section{References}

1. Mackowiak PA, Wasserman SS, Levine MM. A critical appraisal of 98.6 degrees $F$, the upper limit of the normal body temperature, and other legacies of Carl Reinhold August Wunderlich. JAMA. 1992;268:1578-80.

2. Barie PS, Hydo LJ, Eachempati SR. Causes and consequences of fever complicating critical surgical illness. Surg Infect. 2004:5:145-59.

3. Laupland KB, Shahpori R, Kirkpatrick AW, Ross T, Gregson DB, Stelfox HT. Occurrence and outcome of fever in critically ill adults. Crit Care Med. 2008;36:1531-5.

4. Egi M, Morita K. Fever in non-neurological critically ill patients: a systematic review of observational studies. J Crit Care. 2012:27:428-33.

5. Niven DJ, Stelfox HT, Shahpori R, Laupland KB. Fever in adult icus: an interrupted time series analysis. Crit Care Med. 2013:41:1863-9.

6. Rincon F, Hunter K, Schorr C, Dellinger RP, Zanotti-Cavazzoni S. The epidemiology of spontaneous fever and hypothermia on admission of brain injury patients to intensive care units: a multicenter cohort study. J Neurosurg. 2014;121:950-60.

7. Saxena M, Young P, Pilcher D, Bailey M, Harrison D, Bellomo R, et al. Early temperature and mortality in critically ill patients with acute neurological diseases: trauma and stroke differ from infection. Intensive Care Med. 2015:41:823-32.

8. Fernandez A, Schmidt JM, Claassen J, Pavlicova M, Huddleston D, Kreiter KT et al. Fever after subarachnoid hemorrhage: risk factors and impact on outcome. Neurology. 2007;68:1013-9.

9. Schwarz S, Hafner K, Aschoff A, Schwab S. Incidence and prognostic significance of fever following intracerebral hemorrhage. Neurology. 2000;54:354-61

10. Pj Y, Saxena M, Beasley R, Bellomo R, Bailey M, Pilcher D, et al. Early peak temperature and mortality in critically ill patients with or without infection. Intensive Care Med. 2012:38:437-44.

11. Schortgen F, Clabault K, Katsahian S, Devaquet J, Mercat A, Deye N, et al. Fever control using external cooling in septic shock: a randomized controlled trial. Am J Respir Crit Care Med. 2012;185:1088-95.

12. Young P, Saxena M, Bellomo R, Freebairn R, Hammond N, Van Haren F, et al. Acetaminophen for fever in critically ill patients with suspected infection. N Engl J Med. 2015;373:2215-24.

13. Saxena MK, Taylor C, Billot L, Bompoint S, Gowardman J, Roberts JA, et al. The effect of paracetamol on core body temperature in acute traumatic brain injury: a randomised, controlled clinical trial. Plos One. 2015; 10:E0144740

14. Andrews PJ, Sinclair HL, Rodriguez A, Harris BA, Battison CG, Rhodes JK, et al. Hypothermia for intracranial hypertension after traumatic brain injury. $\mathrm{N}$ Engl J Med. 2015;373:2403-12.

15. Robertson CS, Ropper AH. Getting warmer on critical care for head injury. N Engl J Med. 2015;373:2469-70.

16. Search filters for Medline in Ovid Syntax and the PubMed translation. Hamilton, ON: Health Information Research Unit, McMaster University; 2016. Http://Hiru.Mcmaster.Ca/Hiru/Hiru_Hedges_Medline_Strategies.Aspx. Accessed 15 Jan 2016.

17. Laupland KB. Fever in the critically ill medical patient. Crit Care Med. 2009;37:S273-8. 
18. Niven DJ, Leger C, Stelfox HT, Laupland KB. Fever in the critically ill: a review of epidemiology, immunology, and management. J Intensive Care Med. 2012;27:299-306

19. O'grady NP, Barie PS, Bartlett JG, Bleck T, Carroll K, Kalil AC, et al. Guidelines for evaluation of new fever in critically ill adult patients: 2008 update from the American College of Critical Care Medicine and the Infectious Diseases Society of America. Crit Care Med. 2008:36:1330-49.

20. Dinarello CA, Cannon JG, Wolff SM. New concepts on the pathogenesis of fever. Rev Infect Dis. 1988;10:168-89.

21. Denborough M. Malignant hyperthermia. Lancet. 1998;352:1131-6.

22. Niven D, Laupland K, Tabah A, Vesin A, Rello J, Koulenti D, et al. Diagnosis and management of temperature abnormality in icus: a Eurobact Investigators Survey. Crit Care. 2013;17:R289.

23. Niven DJ, Gaudet JE, Laupland KB, Mrklas KJ, Roberts DJ, Stelfox HT. Accuracy of peripheral thermometers for estimating temperature: a systematic review and meta-analysis. Ann Intern Med. 2015;163:768-77.

24. Bouchama A, Knochel JP. Heat stroke. N Engl J Med. 2002;346:1978-88.

25. Margetic B, Aukst-Margetic B. Neuroleptic malignant syndrome and its controversies. Pharmacoepidemiol Drug Saf. 2010;19:429-35.

26. Boyer EW, Shannon M. The serotonin syndrome. N Engl J Med. 2005;352:1112-20.

27. Tenner AG, Halvorson KM. Endocrine causes of dangerous fever. Emerg Med Clin North Am. 2013:31:969-86.

28. Bouchama A, Dehbi M, Mohamed G, Matthies F, Shoukri M, Menne B. Prognostic factors in heat wave related deaths: a meta-analysis. Arch Intern Med. 2007;167:2170-6.

29. Garner JS, Jarvis WR, Emori TG, Horan TC, Hughes JM. CDC definitions for nosocomial infections. In: Olmsted RN, editor. Apic infection control and applied epidemiology: principles and practice. St Louis, MO: Mosby; 1996. p. A1-20.

30. Malacarne $P$, Langer M, Nascimben E, Moro ML, Giudici D, Lampati L, et al. Building a continuous multicenter infection surveillance system in the intensive care unit: findings from the initial data set of 9,493 patients from 71 Italian intensive care units. Crit Care Med. 2008;36:1105-13.

31. Jain S, Self WH, Wunderink RG, Fakhran S, Balk R, Bramley AM, et al. Community-acquired pneumonia requiring hospitalization among U.S adults. N Engl J Med. 2015;373:415-27.

32. Cohen S, Gerding DN, Johnson S, Kelly CP, Loo VG, Mcdonald LC, et al. Clinical practice guidelines for Clostridium difficile infection in adults: 2010 update by the Society for Healthcare Epidemiology of America (Shea) and the Infectious Diseases Society of America (ldsa). Infect Control Hosp Epidemiol. 2010;31:431-55.

33. Tambyah PA, Maki DG. Catheter-associated urinary tract infection is rarely symptomatic: a prospective study of 1,497 catheterized patients. Arch Intern Med. 2000;160:678-82.

34. Laupland KB, Ross T, Pitout JD, Church DL, Gregson DB. Community-onset urinary tract infections: a population-based assessment. Infection. 2007;35:150-3.

35. Bagshaw SM, Laupland KB. Epidemiology of intensive care unit-acquired urinary tract infections. Curr Opin Infect Dis. 2006;19:67-71.

36. Niven DJ, Shahpori R, Stelfox HT, Laupland KB. Management of febrile critically ill adults: a retrospective assessment of regional practice. Ther Hypothermia Temp Manag. 2011;1:99-104.

37. Laupland KB, Gregson DB, Zygun DA, Doig CJ, Mortis G, Church DL. Severe bloodstream infections: a population-based assessment. Crit Care Med. 2004:32:992-7

38. Pronovost $P$, Needham D, Berenholtz $S$, Sinopoli $D, C$ hu $H$, Cosgrove $S$, et al. An intervention to decrease catheter-related bloodstream infections in the ICU. N Engl J Med. 2006;355:2725-32.

39. Pronovost PJ, Watson SR, Goeschel CA, Hyzy RC, Berenholtz SM. Sustaining reductions in central lineassociated bloodstream infections in Michigan intensive care units: a 10-year analysis. Am J Med Qual. 2016;31(3):197-202.

40. Lucet JC, Bouadma L, Zahar JR, Schwebel C, Geffroy A, Pease S, et al. Infectious risk associated with arterial catheters compared with central venous catheters. Crit Care Med. 2010;38:1030-5.

41. O'horo JC, Maki DG, Krupp AE, Safdar N. Arterial catheters as a source of bloodstream infection: a systematic review and meta-analysis. Crit Care Med. 2014;42:1334-9.

42. Wisplinghoff $H$, Bischoff $T$, Tallent $S M$, Seifert $H$, Wenzel RP, Edmond MB. Nosocomial bloodstream infections in US hospitals: analysis of 24,179 cases from a prospective nationwide surveillance study. Clin Infect Dis. 2004;39:309-17
43. Hidron Al, Edwards JR, Patel J, Horan TC, Sievert DM, Pollock DA, et al. NHSN annual update: antimicrobial-resistant pathogens associated with healthcare-associated infections: annual summary of data reported to the National Healthcare Safety Network at the Centers for Disease Control and Prevention, 2006-2007. Infect Control Hosp Epidemiol. 2008;29:996-1011.

44. Stein M, Caplan ES. Nosocomial sinusitis: a unique subset of sinusitis. Curr Opin Infect Dis. 2005;18:147-50.

45. Rabinstein AA, Sandhu K. Non-infectious fever in the neurological intensive care unit: incidence, causes and predictors. J Neurol Neurosurg Psychiatry. 2007;78:1278-80.

46. Barie PS, Eachempati SR. Acute acalculous cholecystitis. Gastroenterol Clin North Am. 2010;39:343-57.

47. Garibaldi RA, Brodine S, Matsumiya S, Coleman M. Evidence for the noninfectious etiology of early postoperative fever. Infect Control. 1985;6:273-7.

48. Kilpatrick MM, Lowry DW, Firlik AD, Yonas H, Marion DW. Hyperthermia in the neurosurgical intensive care unit. Neurosurgery. 2000;47:850-5.

49. Commichau C, Scarmeas N, Mayer SA. Risk factors for fever in the neurologic intensive care unit. Neurology. 2003;60:837-41.

50. Geffroy A, Bronchard R, Merckx P, Seince PF, Faillot T, Albaladejo P, et al. Severe traumatic head injury in adults: which patients are at risk of early hyperthermia? Intensive Care Med. 2004;30:785-90.

51. Hocker SE, Tian L, Li G, Steckelberg JM, Mandrekar JN, Rabinstein AA. Indicators of central fever in the neurologic intensive care unit. JAMA Neurol. 2013;70:1499-504.

52. Golob Jr JF, Claridge JA, Sando MJ, Phipps WR, Yowler CJ, Fadlalla AM, et al. Fever and leukocytosis in critically ill trauma patients: it's not the urine. Surg Infect. 2008;9:49-56.

53. Claridge JA, Golob Jr JF, Fadlalla AM, Malangoni MA, Blatnik J, Yowler CJ. Fever and leukocytosis in critically ill trauma patients: it is not the blood. Am Surg. 2009;75:405-10.

54. Claridge JA, Golob Jr J, Leukhardt WH, Sando MJ, Fadlalla AM, Peerless JR, et al. The "fever workup" and respiratory culture practice in critically ill trauma patients. J Crit Care. 2010:25:493-500.

55. Coburn B, Morris A, Tomlinson G, Detsky AS. Does this adult patient with suspected bacteremia require blood cultures? JAMA. 2012;308:502-11.

56. Circiumaru B, Baldock $G$, Cohen J. A prospective study of fever in the intensive care unit. Intensive Care Med. 1999;25:668-73.

57. Peres Bota D, Lopes Ferreira F, Mélot C, Vincent JL. Body temperature alterations in the critically ill. Intensive Care Med. 2004;30:811-6.

58. Gozzoli V, Schöttker P, Suter PM, Ricou B. Is it worth treating fever in intensive care unit patients? Preliminary results from a randomized trial of the effect of external cooling. Arch Intern Med. 2001;161:121-3.

59. Niven DJ, Stelfox HT, Leger C, Kubes P, Laupland KB. Assessment of the safety and feasibility of administering anti-pyretic therapy in critically ill adults: a pilot randomized clinical trial. J Crit Care. 2013;28:296-302. 